\title{
EVALUASI KUALITAS RUANG FASILITAS UNTUK PASIEN JANTUNG DI SURABAYA BERBASIS PERSEPSI PENGGUNA
}

\author{
Gunawan Tanuwidjaja1, Christine Wonoseputro², dan Sastra Budihardja ${ }^{3}$ \\ 1 \& 2 Program Studi Arsitektur, Universitas Kristen Petra, Indonesia \\ 3 Biro Pusat Pengembangan Karir, Universitas Kristen Petra, Indonesia
}

\begin{abstract}
ABSTRAK
Rumah Sakit harus didesain dengan baik sehingga mampu memenuhi kebutuhan pelayanan kesehatan paripurna. Desain Rumah Sakit harus juga lebih ramah terhadap pasien Rumah Sakit sesuai standar mutu pelayanannya. Penyebab terbanyak penyakit jantung (cardiovasculer desease) ialah atherosclerosis dan/atau darah tinggi (hypertension). Berbagai faktor yang mempengaruhi ialah usia perubahan fisiologi dan morfologi fungsi kardiovaskuler. Fasilitas Penanganan Jantung penting untuk diteliti kualitas ruang dan dampaknya pada pasien. Penelitian ini merupakan penelitian kualitatif mengenai kualitas ruang Rumah Sakit Jantung (ukuran ruang dan warna). Metode dokumentasi yang dipilih ialah menggunakan Metode Visual Research oleh Sanoff (1991) dan analisis terhadap denah yang ada. Kemudian dilakukan wawancara pada keluarga pasien untuk mengetahui persepsi mereka. Hasilnya diharapkan dapat memberi masukan bagi panduan desain fasilitas Penanganan Jantung yang sesuai dengan sosial budaya Indonesia.
\end{abstract}

Kata kunci: jantung, kualitas ruang, ukuran ruang, warna, visual research, riset kualitatif

\section{Pendahuluan}

Cardiovascular disease sebenarnya berkaitan pada berbagai penyakit yang terkait dengan sistem kardiovaskuler (cardiovascular system), seperti: penyakit jantung, penyakit pembuluh darah otak dan ginjal, dan penyakit arteri peripheral (Bridget \& Fuster, 2010). Penyebab penyakit jantung beragam, tetapi biasanya terbanyak ialah atherosclerosis dan/atau darah tinggi (hypertension). Hal ini sering disebabkan oleh faktor usia, perubahan-perubahan fisiologi dan morfologi serta fungsi kardiovaskuler (Dantas et al, 2012).

Penyakit kardiovaskular merupakan penyakit pembunuh pertama di dunia sejak tahun 1970. Karena perkembangan tekonologi kesehatan, tingkat mortalitas akibat penyakit jantung telah menurun pada di negara-negara maju. Tetapi sebaliknya jumlah mortalitasnya meningkat di negara-negara yang memiliki penghasilan rendah dan menengah. Kebanyakan penyakit ini diderita oleh pasien usia yang senja, tetapi ternyata dapat menyerang kanak-kanak. Berbagai terapi untuk mengurangi ancaman ini dengan makan makanan yang sehat, berolahraga dan mengurangi merokok (Valentin, 2010; Mendis et al, 2011; McGill et al 2008). Desain fasilitas penanganan jantung penting untuk diteliti, terutama pada kualitas ruang dan dampaknya pada pasien.

Studi lain tentang kualitas ruang rawat inap untuk Pasien Paliatif oleh Anderson (2008), menyatakan ternyata ada delapan hal yang mempengaruhi suasana hati pasien dan keluarga: ukuran kamar, kebisingan, cahaya, penyimpanan, temperatur, warna, 
kamar kecil, dan ruang sosial. Pasien jantung yang dalam status akut juga membutuhkan kualitas ruang yang dapat menenangkan pasien ketika dirawat. Karena itu, kualitas ruang untuk Paviliun Jantung Rumah Sakit X sangat perlu untuk diteliti.

Sebuah Fasilitas Perawatan Jantung yang baik seharusnya memiliki fasilitas yang terintegrasi antara pemeriksaan, perawatan, dan terapi. Tetapi fasilitas ini juga memberikan ketenangan pada pasien. Rumusan masalah riset ini ialah: apakah ruangruang yang digunakan untuk perawatan pasien dalam fasilitas penanganan jantung memiliki kualitas arsitektur yang menarik secara kualitatif menurut keluarga pasien? Karena keterbatasan waktu, aspek yang diukur hanya terkait pada aspek ukuran ruang, warna, sehingga tujuan penelitian ini ialah melakukan evaluasi kualitas ruang terhadap fasilitas penanganan jantung di Surabaya.

Ruang lingkup penelitian dibatasi karena kesulitan dalam perijinan RS X di Surabaya. Hanya Paviliun RS Jantung saja yang diamati. Tetapi riset akan dikembangkan pada tahun mendatang di RS yang sama atau RS serupa di kota lain.

\section{Studi Literatur}

Desain berkelanjutan harus diwadahi dalam desain bangunan dengan Strategi Desain Berkelanjutan yang diusulkan oleh UIA dalam Deklarasi Kopenhagen yang terkait dengan Desain Inklusif (http://www.uia-architectes.org). Dua rekomendasi yang tercantum di dalam strategi tersebut ialah: desain yang berkelanjutan dalam upaya untuk meningkatkan kualitas hidup, mempromosikan keadilan baik lokal maupun global, memajukan kesejahteraan ekonomi, dan memberikan kesempatan bagi keterlibatan masyarakat dan pemberdayaan; serta desain yang berkelanjutan mendukung pernyataan UNESCO bahwa keragaman budaya, sebagai sumber pertukaran, inovasi dan kreativitas, adalah sangat diperlukan untuk manusia seperti halnya keanekaragaman hayati untuk alam. Kualitas ruang yang diperlukan pasien jantung dan keluarganya yang sesuai kondisi sosial-budaya di Indonesia perlu diteliti.

Kunders (2004) mengungkapkan prinsip-prinsip perencanaan, perancangan dan pengoperasian rumah sakit yang diperlukan adalah: kualitas yang tinggi dalam perawatan pasien, orientasi komunitas yang efektif, viabilitas ekonomi, dan rencana arsitektur yang masuk akal. Salah aspek tersebut ialah kualitas ruang rawat Inap. Hatmoko et al (2010) mengungkapkan berbagai isu rumah sakit dewasa ini dapat dibagi dalam 4 (empat) kategori, yaitu yang terkait dengan isu strategis, isu fungsional, isu teknikal, dan isu prilaku (behavioral).

Pada ranah isu fungsional juga terdapat beberapa hal yang menjadi isu kontemporer, seperti: dimensi, rasio, dan faktor temporal: sampai seberapa besar fungsi-fungsi yang ada perlu diwadahi? Selain itu juga pada aspek teknikal. Aspek visual seperti cahaya dan warna: bagaimana pencahayaan yang ideal untuk masing-masing fungsi? Bilamana cahaya alami dibutuhkan dan bilamana cahaya buatan dibutuhkan? Warna hangat atau warna dinginkah yang lebih kondusif bagi penyembuhan? Kenyamanan thermal juga penting dalam kondisi tidak ber-AC: bagaimana mengupayakan kenyamanan thermal yang optimal? Bilamana dan dengan sistem apa pengkondisian suhu dan kelembaban akan digunakan? Bagaimana menata orientasi bangunan dan bukaan bidang bangunan agar kenyamanan thermal dapat terjaga (Hatmoko et al, 2010)?

Terdapat juga isu-isu yang paling dekat dengan manusia selaku pemakai, yaitu isu behavioral, antara lain (Hatmoko et al., 2010):

- Bagaimana citra bangunan dan lingkungan rumah sakit; 
- Citra ruang-ruang dalam rumah sakit: bagaimana citra pada masing-masing bagian Rumah Sakit? Bagaimana menyesuaikan citra sesuai pengguna? Bagaimana menyesuaikan citra sesuai pemanfaatan ruang?;

- Akomodasi perilaku manusia: perilaku manusia apa saja yang perlu diakomodasi?

Terkait dengan studi prilaku maka perlu disadari tentang arsitektur prilaku dalam desain. Arsitek, pemilik bangunan, dan pengguna bangunan seringkali berasal dari lingkungan budaya yang berbeda. Hal ini menyebabkan preferensi yang berbeda. Dalam hal ini proses akulturasi, baik bagi arsitek maupun calon penggunanya, dapat mempengaruhi keberhasilan sebuah desain (Laurens, 2001; Allport 1985) menjelaskan tentang kaitan pengguna dengan Psikologi Sosial. Psikologi Sosial adalah studi ilmiah tentang bagaimana pikiran, perasaan, dan perilaku masyarakat dipengaruhi oleh aktual, hal yang dibayangkan, atau tersirat dengan kehadiran orang lain. Berdasarkan metode empiris, thoughts (pikiran), feelings (perasaan) dan behaviors (perilaku) manusia dapat dijelaskan.

Zanden (1984), dalam Social Psychology mengungkapkan bahwa tindakan manusia atau sikap dapat dijelaskan sebagai kecenderungan yang relatif sebagai hasil belajar atau rekomendasi awal untuk mengevaluasi seseorang, kejadian, atau situasi. Hal ini dilakukan dengan cara tertentu dan berperilaku sesuai dengan evaluasi tersebut. Di dalamnya terdapat 3 komponen sikap yaitu Cognitive (Kognisi), Affective (Afeksi) dan Behavior (Prilaku). Cognitive gambaran mental mengenai suatu hal yang dimiliki oleh seseorang. Affective adalah perasaan atau emosi mengenai objek, kejadian, atau situasi yang muncul dari seseorang. Terakhir, Behavior adalah kecenderungan atau disposisi untuk berperilaku sesuai dengan referensi tertentu terhadap objek, kejadian atau situasi tertentu.

Dilani (2009) dalam Psychosocially Supportive Design - Scandinavian Healthcare Design mengungkapkan bahwa pasien seringkali diasumsikan sebagai objek dan diobati secara tidak terintegrasi. Fasilitas kesehatan telah ditafsirkan sebagai lingkungan medis-teknis berorientasi pada kebutuhan fisik dari pengobatan ini. Sehingga fasilitas kesehatan sering diartikan sempit sebagai pengurangan risiko terkena penyakit. Dan seringkali strategi menenangkan pasien dan membuat mereka merasa santai tidak diperhatikan. Selain itu juga, bahwa psikologis, sosial dan kebutuhan rohani pasien sebagian besar diabaikan dalam desain fasilitas kesehatan, dan sering terpinggirkan dalam filsafat memberikan perawatan.

Penelitian ilmiah selama dekade terakhir telah membuktikan hubungan antara lingkungan fisik yang buruk atau lingkingan fisik yang tidak mendukung secara psikologis, dengan gejala kesehatan yang buruk. Seperti kecemasan depresi, tekanan darah yang tinggi, sulit tidur, dan peningkatan kebutuhan akan obat analgesik (Dilani, 2009). Stress dapat disebabkan awalnya oleh lingkungan fisik sebagai orgabisasi sosial secara struktur dan fungsi. Sebuah model teori penyakit yang dimediasi psikososial. Kombinasi dari psychosocial stimuli (rangsangan psikososial) dan psycho-biological programs (program psikososial) menentukan psychological and physiological reaction (reaksi psikologi dan fisik) seperti mekanisme stress setiap orang. Hal ini dipengaruhi faktor-faktor lain seperti penyakit awal dan jenis penyakit tersebut. Dengan menyiapkan faktor-faktor yang menunjang kesehatan dan menciptakan lingkungan yang mendukung secara psikososial maka hal ini dapat diatasi (Levi, L., 1972).

Evidence-based design (EBD) atau Desain Berbasis Bukti untuk Rumah Sakit mulai dikembangkan pada kuartal terakhir abad ke-20 karena rumah sakit sebelumnya efisien tetapi buta terhadap kebutuhan emosional pasien. Pada 1990-an, Center for 
Health Design (Pusat Desain Kesehatan), sebuah organisasi non-profit, yang berkomitmen untuk memajukan desain dalam pengaturan kesehatan untuk meningkatkan hasil (dari pengobatan) pasien. Mereka meluncurkan Proyek Pebble tahun 2000 untuk mendorong adopsi metodologi, pengumpulan data penelitian yang ketat dan kolaborasi untuk desainer kesehatan. Evidence-based design (EBD) atau Desain Berbasis Bukti digunakan dengan data yang kredibel dan penelitian untuk mempengaruhi keputusan desain lingkungan Rumah Sakit. Tujuan dari proyek ini adalah untuk menciptakan tambahan wawasan tentang lingkungan kesehatan yang menguntungkan. Penelitian dari Proyek Pebble mengkonfirmasikan bahwa stres pasien dan keadaan emosional mempengaruhi hasil klinis (Novak \& Richardson, 2012). Anderson (2008), juga menemukan pada desain unit perawatan paliatif atau unit perawatan penyakit yang bersifat tidak dapat disembuhkan (Palliative Care Unit Design), ada delapan hal yang mempengaruhi suasana hati pasien dan keluarga pasien paliatif (penyakit yang berat) di antaranya ialah: ukuran kamar, kebisingan, cahaya, penyimpanan, temperatur, warna, kamar kecil, dan ruang sosial (Lihat Tabel 1).

\section{Tabel 1. Identifikasi Kategori dan Tema}

\begin{tabular}{|c|c|}
\hline 1. Realitas Eksternal & 2. Pengalaman Internal \\
\hline 1) Ukuran kamar & 1) Jenis kamar \\
\hline 2) Penyimpanan & a) preferensi: tunggal, bersama, ruang bangsal \\
\hline a) pribadi & b) perasaan / suasana hati ketika di kamar \\
\hline b) peralatan & 2) Otonomi \\
\hline 3) Cahaya & a) privasi \\
\hline a) alami & b) kontrol \\
\hline b) buatan & 3) ruang Bersama \\
\hline 4) Kebisingan & a) persahabatan yang mendukung \& interaksi \\
\hline 5) Suhu kamar & sosial \\
\hline 6) Warna ruang & b) kompatibilitas pasien \\
\hline 7) Kamar kecil \& wastafel di kamar pasien & c) proses kematian dan sekarat yang teramati \\
\hline 8) Ruang Sosial & d) pengalaman pengunjung \\
\hline $\begin{array}{l}\text { a) ruang keluarga, lounge, ruangan yang tenang } \\
\text { b) kafeteria }\end{array}$ & $\begin{array}{l}\text { e) perasaan aman sebagai pasien tidaklah } \\
\text { sendirian }\end{array}$ \\
\hline c) pintu masuk utama \& lobi & 4) Tahap perawatan dan jenis kamar \\
\hline d) aula & a) STP vs LTP \\
\hline 9) Udara / ventilasi & b) kebutuhan akan privasi sebagai kemajuan \\
\hline 10) Perabotan & penyakit \\
\hline 11) Dapur \& fasilitas binatu & 5) Pasien dipindahkan sebagai \\
\hline 12) Lokasi PCU di rumah sakit & indikasi akan kematian yang dekat \\
\hline \multicolumn{2}{|c|}{$\begin{array}{l}\text { Catatan:. Tema yang dicetak tebal mengindikasikan preferensi anggota keluarga, yang tidak, disebutkan } \\
\text { oleh pasien (semua tema lain dalam teks biasa disebutkan oleh kedua pasien dan keluarga). Tema tidak } \\
\text { dalam urutan tertentu. }\end{array}$} \\
\hline
\end{tabular}

Novak \& Richardson (2012) mengutip Teori Warna Luscher (1969). Prof Dr Max Luscher adalah kepala Institut Diagnostik Psiko-medis di Lucern (Swiss) dan mempelajari psikiatri klinis, filsafat dan psikologi di Basel, Swiss. Dia berteori bahwa perasaan manusia tentang warna tertentu didasarkan pada pengalaman manusia dengan warna itu. Sebagai contoh, asosiasi umum ketenangan dengan warna hijau mungkin merupakan hasil dari manusia purba penggunaan hutan hijau subur atau hutan sebagai pelarian dari lahan terbuka, sinar matahari, ataupun dari tempat di mana ia akan terlihat. Hutan dianggap sebagai tempat istirahat dan pemulihan. "Kelangsungan 
hidup kita berarti memahami apa yang alam beritahukan dan komunikasikan pada kita melalui warna."

Rumah Sakit Elmhurst Memorial dirancang berdasarkan Prairie School of Design, Midwestern, pinggiran kota Chicago. The Prairie Style dicirikan oleh panjang, garis horizontal yang menarik mata ke pemandangan sekitarnya. Selaras dengan alam dan isyarat gambar dari empat musim tahunan Midwestern, warna gaya Prairie sering terinspirasi dari palet tanah. Berbagai warna dapat mencakup hijau pupus segar yang ditemukan dalam pertumbuhan pertama musim semi ke daun hijau yang lebih tua dan rumput musim panas. Musim semi dan musim panas juga mendatangkan munculnya warna dari mekar bunga termasuk merah, kuning, putih, ungu, dan biru (red, yellow, white, purple and blue). Ochre, kuning, emas, merah api, jeruk, dan merah anggur (ochre, amber, gold, fire red, oranges and deep burgundy) yang lebih dalam diwarnai dengan warna daun dan tanaman musim gugur. Cokelat dan abu-abu (browns and grays) yang terpampang di cabang-cabang pohon gundul dan batang menjelang musim dingin tiba (Novak \& Richardson, 2012).

Contoh Kualitas Ruang RS Jantung yang baik ditemukan pada Sanford Heart Hospital yang baru di Sioux Falls, South Dakota. Rumah sakit ini didesain oleh Ellerbe Becket dan dibangun oleh Henry Carlson Company. Letak rumah sakit ini terdapat di dalam kompleks Sanford USD Medical Center. Dengan total luas 205.000 kaki persegi Rumah Sakit Jantung ini memiliki konsep yang memperkenalkan perawatan jantung pribadi yang sangat maju, dan terintegrasi (http://www.healthcaredesignmagazine.com). Rumah Sakit ini dibangun dengan proses partisipatif di mana arsitek dan pembangun menerima umpan balik dari dokter, perawat, peneliti, staf, pasien jantung, dan mantan pasien. Jadilah sebuah bangunan yang memiliki fitur khusus yakni Sanford Heart Hospital dengan desain Gothik yang ramah lingkungan.

Konsep arsitektur ini diperluas pada berbagai ruang utama yang menggunakan material yang tahan lama sekaligus alami, seperti kayu dan batu yang merefleksikan ketahanan yang lama dan panjang umur. Seorang concierge (penyambut) akan menyambut pasien dan keluarga pasien saat datang dan membantu berorientasi dalam perjalanan penyembuhan pasien. Perabotan yang nyaman dan bernilai seni juga memberikan kesan Rumah Sakit yang stress - free (tidak menimbulkan stress) dan familiar (dikenal) (Kennedy et al, 2012).

Sanford Heart Hospital Sioux Falls memiliki perawatan kardiovaskular inovatif termasuk kamar operasi, laboratorium kateterisasi yang terbaru untuk pelaksanaan operasi jantung, prosedur, dan terapi. Fasilitas-fasilitas ini mencakup (http://www.healthcaredesignmagazine.com/news-item/sanford-health-opens-hearthospital):

- $\quad$ Siemens Artis Zeego Imaging system dengan yang memiliki lengan robot canggih untuk pembedahan yang sulit.

- Hybrid Operating Room (Hybrid OR) atau Kamar Operasi Hibrid yang memiliki sistem yang canggih mejadikan dokter dapat mengganti katup jantung pasien dengan aman dan mudah tanpa operasi pembukaan dada.

- Hybrid OR juga ideal untuk pasien yang juga membutuhkan operasi tradisional.

- Cardiovascular operating room (CV OR) atau Kamar Operasi Kardiovaskular dilengkapi dengan teknologi canggih yang mengubah cara perawatan pasien jantung. 
- $\quad$ The boom-mounted equipment (peralatan yang terpasang pada langit - langit) menjaga lantai tidak menjadi kacau dan memungkinkan tim sebanyak delapan sampai sepuluh tenaga profesional untuk bergerak dengan aman dan efisien.

- Post-Anesthesia Care Unit (PACU) disediakan yang mana mencakup kamar konsultasi pribadi untuk ahli bedah berkomunikasi dengan keluarga pasien dan sistem pendukung segera pasca operasi.

- The Clinical Surgical Suite Guest area (Ruang Tamu untuk Kamar Operasi) disediakan agar penunggu pasien dapat duduk bersantai, menikmati kopi, dan menikmati suasana rumah yang nyaman.

- Ukuran kamar pasien yang besar juga disediakan untuk pasien dan keluarganya.

- Acuity adaptable care private patient rooms (Ruang perawatan pasien yang adaptif) didesain dengan lingkungan yang tenang, memudahkan pemantauan bagi staf perawat dan suasana layaknya rumah bagi pasien dan keluarga.

Penjelasan lebih detail tentang Kamar Pasien di Rumah Sakit Jantung Sanford: Rumah Sakit Jantung Sanford, memiliki tampilan digital untuk menyampaikan pesan dan memberikan informasi yang penting untuk menghasilkan pelayanan yang bersih dan terkonsolidasi. Peralatan keselamatan yang state-of-the-art disediakan untuk membantu staf dan menyediakan cara yang aman bagi pasien untuk bergerak di dalam kamar mereka. Lift plafon menyediakan cara yang aman bagi pasien untuk bergerak dari tempat tidur mereka ke kamar mandi tanpa melelahkan staf. Kamar mandi memiliki pintu selebar 42 inch, grab bar (railing genggam), showers untuk kursi roda, dan pencahayaan yang diaktifkan dengan gerakan yang semuanya memberikan rasa aman kepada pasien serta menjamin keselamatan dan keamanan. Laci pengiriman khusus disediakan di dinding luar kamar pasien untuk memungkinkan karyawan apotek memberikan obat dan bahan lainnya tanpa harus mengganggu waktu istirahat pasien. Kotak air dialisis juga dirancang dengan koneksi yang mudah ke sumber air yang diperuntukkan bagi pasien yang membutuhkan dialisis selama mereka tinggal. Seni dan musik telah lama dikenal untuk menghibur dan menenangkan jiwa dan tubuh manusia. Seni juga ditemukan meningkatkan kecepatan pemulihan dan juga mendukung perjuangan pasien dan keluarga. (http://www.healthcaredesignmagazine.com).

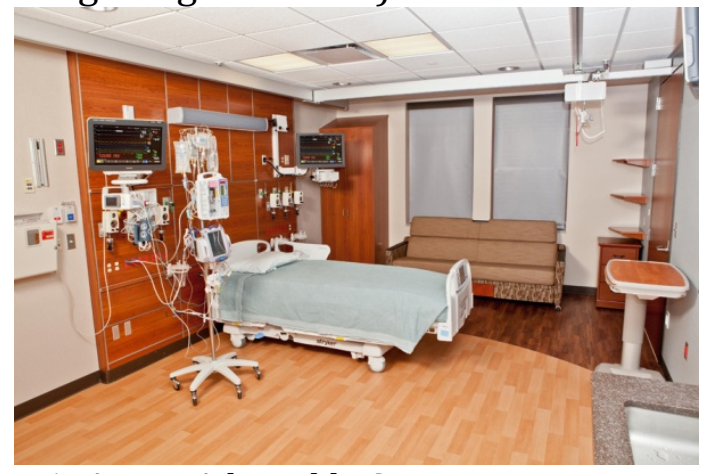

Gambar 1. Acuity Adaptable Care Private Patient Rooms

(Sumber: http://www.sanfordhealth.org/MedicalServices/COE/Heart)

Sementara contoh lain untuk kualitas ruang rawat inap didapat pada Clarian West Medical Center, Avon Indiana, USA, Interior Kamar Rawat Inap dari Clarian West Medical Center, Avon Indiana, USA memiliki warna yang menarik karena itu kasus ini disertakan dalam studi kasus ini. Clarian West Medical Center, Avon Indiana, USA yang dikelola oleh Indiana University Health yang paling komprehensif di Indiana dan 
bermitra dengan Indiana University School of Medicine, salah satu sekolah terkemuka di kalangan medis, memberikan pasien akses ke perawatan inovatif dan terapi (http://iuhealth.org/ dan Boekel, 2008).

Bahan-bahan alami, termasuk batu, kayu, dan batu tulis, digunakan di seluruh bangunan untuk meneruskan konsep kehangatan pada lahan. Bahan-bahan ini juga menanamkan rasa keabadian dan stabilitas, dan keakraban mereka kepada pasien dan keluarga sehingga membantu meredakan kecemasan. Tetapi bahan alami ini tetap dihaluskan untuk mengamankan penggunaan peralatan seperti kursi roda dll. Langitlangit kayu di ruang publik utama memiliki sifat akustik yang meminimalisir kebisingan dari pemantulan suara oleh permukaan keras di daerah tersebut. Unit langit-langit kayu ceri berukuran 4-kaki kali 4-kaki langit memiliki lubang-lubang kecil yang dibor ke dalam mereka dan peredam suara di dalamnya (http://www.hfmmagazine.com).

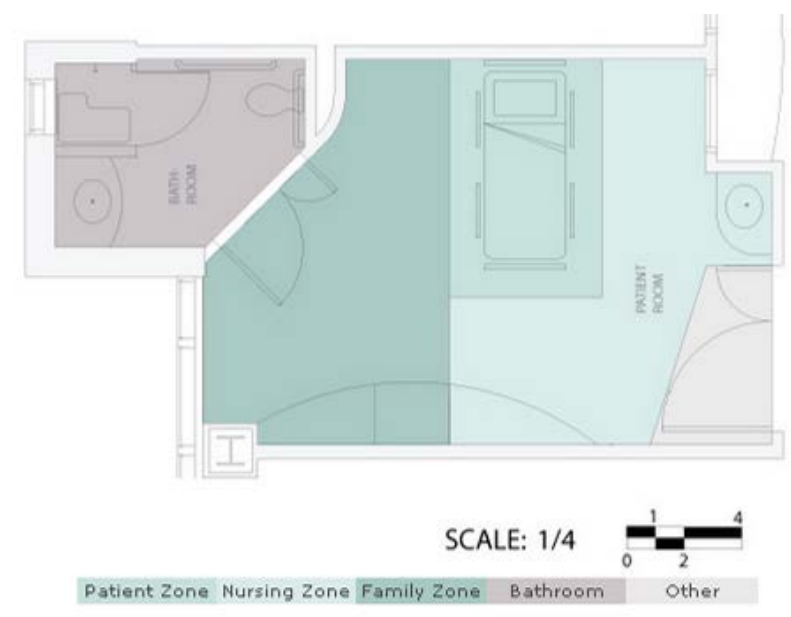

Gambar 2. Denah Kamar Rawat Inap di Clarian West Medical Center (Sumber:

http://healthcaredesignweb.org/HWmem/case/hospital.asp?hospital_id=4\&hospital_name=Clarian\%20 West\%20Medical\%20Center\&id=1)

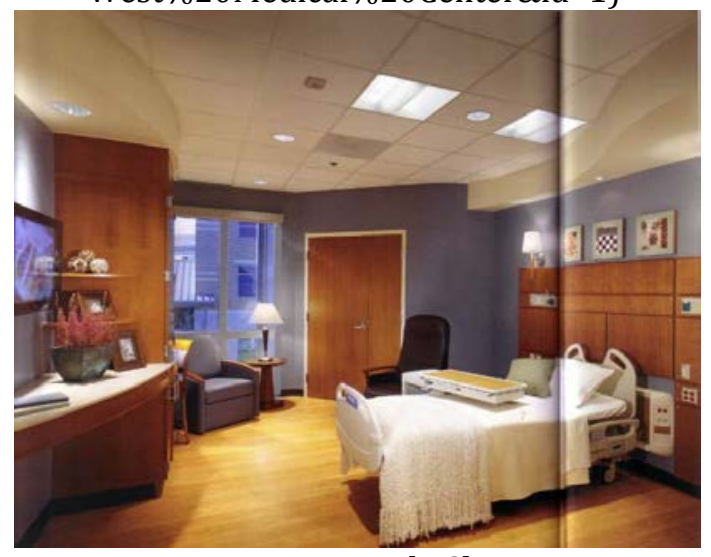

Gambar 3. Foto Kamar Rawat Inap di Clarian West Medical Center (Sumber: Boekel, 2008)

\section{Metode Penelitian}

Penelitian ini merupakan penelitian eksploratif mengenai fungsionalitas rumah sakit jantung dan aksesibilitasnya. Metode dokumentasi yang dipilih ialah menggunakan Metode Visual Research oleh Sanoff (1991). Kemudian dilakukan penyebaran kuesioner terhadap keluarga pasien untuk mengetahui kualitas ruang yang 
ada atau diinginkan terutama terkait dengan ukuran ruang dan warna ruangan (dibatasi dahulu pada 2 aspek).

Langkah dalam penelitian ini adalah:

- Tinjauan pustaka (1 bulan)

- Pengurusan administrasi/ perijinan (1 bulan)

- Pengumpulan data sekunder dari RS / dokumentasi kondisi RS (2 minggu)

- Penyusunan kuesioner (2 minggu)

- Penyebaran kuesioner (2 minggu)

- Analisa kuesioner (2 minggu)

- Penyusunan laporan riset (1 bulan)

\section{Hasil dan Pembahasan}

Cardiovascular disease atau penyakit jantung mereferensikan pada berbagai penyakit yang terkait dengan sistem kardiovaskuler (cardiovascular system). Karena sifat penyakit ini yang sangat kritis, maka diperlukan perawatan pertolongan pertama yang cepat dan perawatan intensif yang terpantau 24 jam, 7 hari seminggu.

Tetapi karena permintaan dokter, maka identitas rumah sakit ini dirahasiakan agar tidak mengganggu nama baik rumah sakit dan kerahasiaan identitas pasien. Sebagai latar belakang, RS X merupakan rumah sakit dengan fasilitas yang lengkap.

Beberapa Ruangan yang tersedia di Paviliun Jantung RS X ini ialah:

- Ruang Pendaftaran

- $\quad$ Ruang Tunggu

- Ruang Rekam Medis dan Ruang Obat

- Dapur

- Ruang Kantor Kepala Sub Departemen Jantung

- Ruang Kepala Ruang

- Ruang Linen dan Ruang Ganti Perawat,

- Toilet Umum

- $\quad$ Ruang Oksigen

- $\quad$ Ruang Spoel Hock

- Ruang Rawat Inap Kelas III

- Kamar Mandi Ruang Rawat Inap Kelas III

- Ruang ICCU

- $\quad$ Nurse Station utk Ruang ICCU

- Ruang Rawat Inap Kelas II

- Kamar Mandi Ruang Rawat Inap Kelas II

- Ruang Rawat Inap Kelas I

- Kamar Mandi Ruang Rawat Inap Kelas I

- Ruang Dokter Muda 

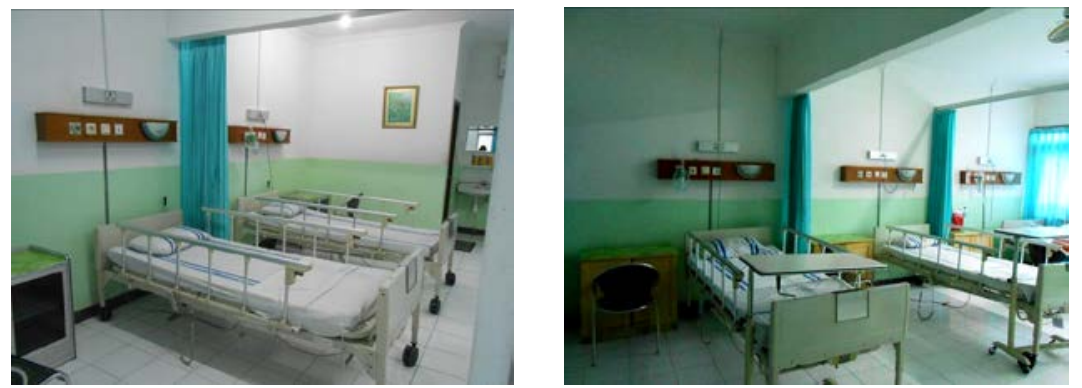

Gambar 4. Foto Ruang Rawat Inap Kelas II dan III di Paviliun RS X

Dilakukan wawancara dengan keluarga pasien yang tinggal di Paviliun Jantung ini. Karena sifat penelitian ini yang bersifat eksploratif maka disusun pertanyaan yang bersifat eksploratif yang terutama terkait dengan ukuran ruang dan warna ruangan (dibatasi dahulu pada 2 aspek), walaupun telah diketahui terdapat faktor-faktor kualitas ruang lainnya dari Anderson (2008), Hatmoko et al (2010) dan Novak \& Richardson (2012). Responden sebanyak 5 orang keluarga pasien dari Kelas II dan Kelasi III. Jumlah ini diambil karena keterbatasan waktu survei karena perijinan dari Rumah Sakit.

Latar belakang responden (keluarga pasien) ini cukup bervariasi. Dari 5 orang responden terdapat 2 orang laki-laki dan 3 orang perempuan. Sementara itu, usia responden bervariasi antara 23, 29, 35, 40, dan 58 tahun. Didapati juga 2 orang responden merupakan lulusan Sarjana dan 3 orang lainnya merupakan lulusan Sekolah Menengah Umum (SMU atau SMA). Profesi mereka berkisar antara Ibu Rumah Tangga, Mahasiswa, Karyawan Swasta, Wirausahawan dan Pensiunan. Mengenai tempat asal, ternyata 1 responden dari Pulau Madura sementara 4 responden berasal dari Surabaya. Terlihat bahwa sampel responden cukup heterogen.

Berkaitan dengan lama mereka tinggal di dalam Ruang Rawat Inap juga ternyata bervariasi antara 2 hari, 4 hari, 8 hari, dan 12 hari. Sementara mereka juga pernah mengunjungi Rumah Sakit lainnya seperti RS. Willliam Booth, RSI Jemursari, RS Husada Utama, RS. Muhammad Anwar [Sumenep], RSUD Dr. Soetomo Surabaya. Hal ini menyebabkan mereka juga memiliki pembanding kualitas ruang di Rumah Sakit lain.

Dapat disimpulkan dari wawancara dengan penunggu/ keluarga pasien tentang Suasana Ruang Rawat Inap ternyata responden seringkali tidak dapat memisahkan antara Cognitive (Kognisi), Affective (Afeksi) dan Behavior (Prilaku). Seringkali responden menjawab hal yang sama untuk ketiga pertanyaan. Hal ini diidentifikasi berkaitan dengan latar belakang warga Indonesia yang tidak membedakan antara ketiga tersebut.

Mengenai ukuran ruang Rawat Inap di Paviliun Jantung RS X, Hatmoko et al (2010) mengungkapkan bahwa standar luas ruangan harus mencapai ialah $24 \mathrm{~m}^{2}$ / Tempat Tidur (TT) untuk Ruang Kelas I, $12 \mathrm{~m}^{2} / \mathrm{TT}$ untuk Ruang Kelas II, 12m²/TT untuk Ruang Kelas III. Karena subjek yang diteliti tinggal di Kelas II dan III maka evaluasi ukuran ruang hanya dilakukan pada Kelas II dan III. Ternyata ukuran ruang Kelas II sudah memenuhi, sedangkan Kelas III lebih kecil dari rekomendasi tersebut.

Sebagai catatan, ditemui terdapat keunikan aktivitas penunggu pasien di Rumah Sakit ini. Ternyata setiap pasien ditunggui oleh salah satu orang keluarga pasien selama 24 jam (biasanya secara bergantian). Dan anggota keluarga ini tidur di lantai di samping tempat tidur pasien atau menggunakan ranjang lipat. Akibatnya, perawat yang akan merawat pasien memiliki ruang gerak yang terbatas. Selain itu, kegiatan tidur di lantai Rumah Sakit dapat berdampak kurang baik pada keluarga pasien karena terpapar 
bakteri atau virus yang menempel di lantai. Sedangkan dua responden di Kelas III menyatakan bahwa ukuran ruang yang tersedia kurang besar untuk kegiatan sholat serta terganggu karena kegiatan keluar masuk karena tempat tidur pasien terletak di depan pintu masuk ruangan.

Ternyata secara umum dari 5 keluarga pasien baik di Kelas II maupun Kelas III menemui bahwa ukurannya memadai secara kognisi (pikiran), dan mereka dapat mengerti keterbatasan ini karena memahami keadaan ekonomi yang membatasi (afeksi dan konasi). Adapula temuan bahwa keluarga pasien ada yang merasa kurang luas (afeksi) tetapi tetap dapat beraktivitas dengan baik (konasi). Hal ini mungkin menunjukkan adaptasi keluarga pasien terhadap kondisi yang ada di RS X dan RS lainnya pada umumnya di Indonesia.

Mengenai kombinasi warna ruang, Ruang Rawat Inap Kelas II dan Kelas III di Paviliun Jantung RS X didominasi oleh warna putih dan hijau muda. Teori Luscher (1969) menyampaikan bahwa dengan warna hijau memberikan nuansa ketenangan tempat istirahat dan pemulihan. Sementara Novak \& Richardson (2012) menyampaikan bahwa hijau secara umum ini ditafsirkan sebagai sejuk atau dingin. Nuansa dan kesan pada warna ini berasal dari panjang gelombang lebih pendek dari spektrum. Warna hijau yang lebih kuning dianggap lebih hangat. Sementara itu, warna hijau yang lebih biru dianggap lebih dingin. Selain itu ia juga mengungkapkan beberapa dampak dari warna ini yaitu: meningkatkan konsentrasi, memfasilitasi evaluasi dokter, mengembangkan relaksasi, menawarkan keseimbangan, meningkatkan keamanan, memberikan suasana yang segar, memperbaharui rohani, menyarankan penyembuhan. Ternyata hal ini disetujui oleh keluarga pasien ini secara pikiran (kognisi). Kelima orang responden mendapatkan kesan bersih, segar, tenang, lembut. Selain itu mereka juga menyukai (afeksi) warna tersebut. Walaupun demikian sebagian besar tidak merasakan perubahan sikap (konasi) pada mereka. Hanya dua responden yang merasakan dampak yang membuat lebih bersemangat.

Perlu dicatat bahwa warna yang diinginkan atau disukai pasien belum tentu sesuai dengan tujuan-tujuan lain dalam Rumah Sakit. Warna utama di sekitar pasien (head bed) direkomendasikan menggunakan warna netral atau tidak mengaburkan kompleksi kulit pasien yang diamati. Hal ini dimaksudkan agar dokter dan perawat dapat melajukan analisis secara tepat (Novak \& Richardson, 2012). Selain itu juga warna-warna lantai dan dinding biasanya dipilihkan yang mudah dibersihkan. Hal ini sesuai dengan rekomendasi (Hatmoko et.al, 2010) bahwa dinding dan langit-langit diusulkan dari bahan yang kuat, tidak berpori, mudah dibersihkan, kedap air dan berwarna terang. Terlihat bahwa warna-warna yang lembut dan akrab dapat digunakan tetapi tetap menggunakan material yang mudah dibersihkan.

Didapati bahwa Kualitas RS X terutama terkait ukuran dan warna ternyata diterima dengan baik oleh responden baik dalam Cognitive (Kognisi), Affective (Afeksi) dan Behavior (Prilaku). Warna putih dan hijau memang ditangkap sebagai bersih, sejuk dan menenangkan sesuai dengan temuan Novak \& Richardson (2012). Tetapi memang terdapat penyesuaian tindakan pada penunggu/ keluarga pasien Kelas III karena keterbatasan ruang yang ada karena kemampuan ekonomi mereka. Hal ini dapat sesuai dengan rekomendasi Dilani (2009), bahwa manusia dapat bereaksi secara konstruktif dan menemukan cara untuk mengatasi masalah jika memiliki pengalaman yang baik akan sekelilingnya. Hal ini juga menunjukkan bahwa manusia dapat menerima atau terpaksa menyukai kualitas ruang ketika memahami kondisinya secara kognitif. 
Memang ada masukan dari pasien tentang perlunya peningkatan privasi di Ruang Rawat Inap dengan melengkapi tirai penutup di unit rawat ini. Hal ini dapat meningkatkan kenyamanan di kedepannya.

Selain menanyakan masukan pasien tentang ukuran luas dan warna RS X, responden juga diminta untuk memberikan pendapat tentang warna dua Rumah Sakit lainnya yang diwakili dengan foto yaitu: Ruang Rawat Inap di Sanford Heart Hospital Sioux Falls (http://www.sanfordhealth.org/MedicalServices/COE/Heart) dan Ruang Rawat Inap di Clarian West Medical Center, Avon Indiana, USA (Boekel, 2008). Ternyata ditemukan bahwa sebagian besar mengaku bahwa lingkungan ini ideal sebagai ruang rawat inap. Tetapi para responden menyadari juga bahwa unit ini tidak dapat diwujudkan di Indonesia karena keterbatasan ekonomi.

Sebagian responden merespon bahwa warna coklat pada Ruang Rawat Inap di Sanford Heart Hospital Sioux Falls (http://www.sanfordhealth.org) kurang sesuai (afeksi) karena warnanya yang terlalu mencolok. Hal ini diprediksi terkait dengan teori Luscher bahwa perasaan manusia tentang warna tertentu didasarkan pada pengalaman manusia dengan warna itu (Luscher, 1969). Warna-warna yang biasanya digunakan di rumah atau bangunan di Indonesia biasanya ialah warna netral dan lembut seperti white, khaki, vanilla, off-white, beige (putih, khaki, teh, vanili, off-white). Karena itu warna coklat tua mungkin kurang sesuai untuk interior rumah sakit di Indonesia.

Sebaliknya warna biru dan coklat pada Ruang Rawat Inap di Clarian West Medical Center, Avon Indiana, USA (Boekel, 2008), disukai oleh sebagian besar responden karena mereka suka (afeksi) dengan keberadaan warna tersebut memberikan kesan tenang, nyaman dan dingin di dalamnya. Hal ini merupakan temuan positif bahwa penunggu/ keluarga pasien juga merasakan konsep warna alami yang diterapkan di Clarian West. Sehingga mungkin warna-warna yang menimbulkan suasana seperti di rumah dapat diterapkan tanpa melanggar standar kebersihan rumah sakit di Indonesia. Misalnya warna-warna termasuk azure, sky blue, ultramarine and navy blue (biru, biru langit, biru laut dan warna angkatan laut). Warna-warna lain dapat diterapkan sejauh tidak terlalu kontras karena kebiasaan masyarakat Indonesia yang menggunakan warna-warna yang tidak terlalu mencolok. Selain itu ternyata didapati bahwa pilihan warna itu dipengaruhi subjektivitas pengguna serta latar belakang pengguna, pendidikan, suku dan usia. Karena itu, memang diperlukan telaah lebih mendalam tentang kaitan antara hal-hal di atas dengan preferensi terhadap warna.

Seringkali juga didapati bahwa pilihan warna Rumah Sakit ini ditentukan oleh pemilik gedung, dokter maupun konsultan perancangan (pengambil-pengambil keputusan). Sehingga preferensi mereka akan sangat mempengaruhi kombinasi warna yang diambil. Beberapa Rumah Sakit akan memiliki warna yang lebih mewakili religiusitas tertentu, makna yang diinginkan dan juga latar belakang para pengambil keputusan ini. Selain itu pencahayaan yang terlalu terang pada Ruang Rawat Inap di Sanford Heart Hospital Sioux Falls kurang sesuai dengan responden. Karena akan mengganggu kemudahan pasien untuk tidur. Diperlukan pencahayaan buatan yang dapat diatur intensitasnya untuk memudahkan pasien untuk beristirahat. Juga diperlukan tirai/ korden untuk mengurangi kesilauan dari sinar matahari tropis.

\section{Kesimpulan dan Saran}

Kesimpulan yang dapat diambil dari penelitian ini adalah: 
- Ukuran ruang RS X ada yang memadai secara standar Rumah Sakit dan lebih kecil dari standar yang ada, tetapi responden dapat menerimanya secara kognisi, afeksi dan konasi. Dan ternyata Responden dapat beradaptasi dengan kondisi ini sesuai dengan teori adaptasi Dilani (2009).

- Mengenai kombinasi warna ruang, Ruang Rawat Inap Kelas II dan Kelas III di Paviliun Jantung RS X didominasi oleh warna putih dan hijau muda. Dan responden ini berpikir (kognisi) dan menyukai (afeksi) karena kesan bersih, segar, tenang, lembut. Selain itu mereka juga menyukai (afeksi) warna tersebut.

- Sementara itu warna coklat pada Ruang Rawat Inap di Sanford Heart Hospital Sioux Falls (http://www.sanfordhealth.org/MedicalServices/COE/Heart) kurang disukai (afeksi) sebagian responden karena warnanya yang terlalu mencolok. Hal ini diprediksi terkait dengan teori Luscher, perasaan manusia terkait dengan warna itu (Luscher, 1969), di mana warna-warna yang biasanya digunakan di rumah atau bangunan di Indonesia biasanya ialah warna netral dan lembut.

- Sebaliknya warna biru dan coklat pada Ruang Rawat Inap di Clarian West Medical Center, Avon Indiana, USA (Boekel, 2008), disukai oleh sebagian besar responden karena mereka suka (afeksi) dengan keberadaan warna tersebut memberikan kesan tenang, nyaman dan dingin di dalamnya. Misalnya warna-warna termasuk azure, sky blue, ultramarine and navy blue (biru, biru langit, biru laut dan warna angkatan laut).

Masih banyak faktor yang perlu diteliti lagi mengenai kualitas ruang untuk Rumah Sakit Jantung ini. Hal ini menjadi rekomendasi untuk riset selanjutnya.

- Warna Ruang dan Cahaya (alami dan buatan)

- Penyimpanan (pribadi pasien dan peralatan medis)

- Kebisingan

- Suhu kamar

Riset ini akan dikembangkan dilanjutkan pada tahun berikutnya di RS lainnya di Surabaya.

\section{Daftar Pustaka}

Allport, G.W. 1985. "The Historical Background of Social Psychology" dalam Lindzey, G; Aronson, E. The Handbook of Social Psychology. New York: McGraw Hill.

Anderson, D. 2008. Palliative Care Unit Design: Patient and Family Preferences, Design \& Health Scientific Review, World Health Design. Source: http://www.designandhealth.com/uploaded/documents/Publications/Papers/ diana-andersson-whd-april08.pdf.

Boekel, A., (ed). 2008. Architecture for Healthcare. Victoria, Australia: The Images Publishing Group Pty Ltd.

Bridget, B.K., Fuster, V. 2010. Promoting Cardiovascular Health in the Developing World: A Critical Challenge to Achieve Global Health. Washington D.C.: Institute of Medicine, National Academies Press.

Committee on Preventing the Global Epidemic of Cardiovascular Disease: Meeting the Challenges in Developing Countries; Fuster, Board on Global Health.

Dantas, A.P., Jimenez-Altayo, F., Vila, E. August 2012. "Vascular Aging: Facts and Factors". Frontiers in Vascular Physiology 3 (325): 1-2.

Dilani, A. 2009. Psychosocially Supportive Design - Scandinavian Healthcare Design in Del Nord, R., (ed). (2009), The Culture for the Future of Healthcare Architecture. 
Proceedings of the 28th, International Public Health Seminar, Penerbit Alinea Editrice.

Hatmoko, A.U., Wulandari, W., Alhamdani, M.R. 2010. Arsitektur Rumah Sakit. Yogyakarta: Global Rancang Selaras.

Kennedy, M., Williamson, K., Denevan, K. 2012. Sanford Heart Hospital, Enduring Architecture for Health in Medical Construction and Design Magazine, November December 2012, page 30-34 retrieved from www.mcdmag.com.

Kunders, G.D. 2004. Hospitals: Facilities Planning and Management. New Delhi: McGrawHill Education.

Laurens, J.M. 2001. Studi Prilaku Lingkungan. Surabaya: Universitas Kristen Petra.

Levi, L. 1972. Psychosocial Factors in Preventive Medicine, in background papers to Healthy People: The Surgeon General's Report on Health Promotion and Disease Prevention. Washington D.C.: US Public Health Service.

Luscher, M. 1969. The Luscher Color Test. New York: Random House.

McGill, H.C., McMahan, C.A., Gidding, S.S. 2008. "Preventing Heart Disease in The 21st Century: Implications of the Pathobiological Determinants of Atherosclerosis in Youth (PDAY) study". Circulation 117 (9): 1216-27.

Mendis, S., Puska, P., Norrving, B.(ed). 2011. Global Atlas on Cardiovascular Disease Prevention and Control.

Novak, C.A., Richardson, B. 2012. Functional Color and Design in Healthcare Environments, Architectural Record, Continuing Education. McGraw Hill, diunduh dari: http://continuingeducation.construction.com/crs.php?L=222\&C=928\#.

Valentin, A., Bridget B.K., (ed). 2010. Promoting Cardiovascular Health in The Developing World: A Critical Challenge to Achieve Global Health. Washington D.C.: Institute of Medicine of the National, National Academies Press.

Zanden, JWV. 1984. Social Psychology, third edition. USA: Random House, Inc.

http://healthcaredesignweb.org/HWmem/case/hospital.asp?hospital_id=4\&hospital_n ame=Clarian $\% 20$ West $\% 20$ Medical\%20Center\&id=1

http://iuhealth.org/

http://www.healthcaredesignmagazine.com/news-item/sanford-health-opens-hearthospital

http://www.hfmmagazine.com/hfmmagazine/jsp/articledisplay.jsp?dcrpath=HFMMAG AZINE/PubsNewsArticleGen/data/03MAR2007/0703HFM_FEA_CoverSTory\&do main=HFMMAGAZINE

http://www.sanfordhealth.org/MedicalServices/COE/Heart

http://www.uia-architectes.org/image/PDF/COP15/COP15_Declaration_EN.pdf 